\title{
Interocular transfer of color aversion in pigeons
}

\author{
DAVID POUNDS, PHYLLIS WILLIAMSON, and CARL CHENEY \\ Utah State University, Logan, Utah 84322
}

\begin{abstract}
An experiment was conducted to investigate the possible interocular transfer of a color aversion. Three groups of eight experimentally naive feral pigeons were exposed to either redor blue-colored water. One-half of these birds wore patches either on the right or on the left eye. Following water consumption, two groups were injected with cyclophosphamide $(120 \mathrm{mg} / \mathrm{kg})$ intraperitoneally. The remaining group was injected with distilled water in the same manner. One-half of the birds' patches were switched to the unexposed eye on the day following treatment. Birds were given $15 \mathrm{~min}$ access to $70 \mathrm{ml}$ of plain water for 2 subsequent days and then were tested for aversion on the 3rd day. Treated birds demonstrated a reduction in colored water consumption, and controls did not. Eye-patch condition did not affect the degree of aversion obtained. Data indicate that an aversion to color learned monocularly transfers passively to the untrained eye. Results are discussed with regard to other interocular transfer literature and the aversion literature.
\end{abstract}

Although there have been relatively few avian species employed in taste aversion studies, quail (Wilcoxin, Dragoin, \& Kral, 1971), hawks (Brett, Hankins, \& Garcia, 1976), and pigeons (Hickis \& Jackson, Note 1) have been reported to avert to a visual (non-flavor) conditional stimulus (CS). Since the optic nerves of pigeons project without mixing to opposite hemispheres, information presented to a single eye is laid down on only the contralateral side (Cowan, Adamson, \& Powell, 1961). While interocular transfer of color (Catania, 1965; Stevens \& Kirsch, in press), color and pattern (Green, Brecha, \& Gazzaniga, 1978), and line-tilt discriminations (Cheney \& Tam, 1972) have been reported in pigeons, failures to obtain transfer following monocular training have also been reported (Catania, 1965; Essock-Vitale, 1979; Graves \& Goodale, 1977; Levine, 1952; Mello, 1965), depending upon the nature of the stimuli, the tasks, and/or the specific brain lesions employed.

The current study investigated whether an illnessinduced aversion that had been paired with colored water would transfer passively to the untrained eye.

\section{METHOD}

\section{Subjects}

Twenty-four experimentally naive feral pigeons were maintained on $15 \mathrm{~min}$ access to water and $20 \mathrm{~h}$ access to food per day.

\section{Apparatus}

Individual home cages served as experimental chambers. Jars placed in the middle of the front cage panel provided access to water. The color stimuli that were the conditional stimuli consisted of red- or blue-colored water obtained by

Aspects of these data were presented at the annual meeting of the Rocky Mountain Psychological Association, Las Vegas, Nevada, April 1979. We thank Keith Wheeler of Mead Johnson for providing the cyclophosphamide. Reprints may be obtained from C. D. Cheney. mixing $6 \mathrm{ml}$ of red or blue food dye in $570 \mathrm{ml}$ of tap water. Cyclophosphamide $(120 \mathrm{mg} / \mathrm{kg})$ was the illness-inducing agent, injected intraperitoneally. Circular Band-Aids secured with rubber cement served as eye patches (Cheney \& Tam, 1972). They were attached and removed very carefully, and none was observed to come loose.

\section{Procedure}

Subjects were randomly divided into three groups. Group 1 served as control, with all treatment conditions represented. The experimental group receiving blue-colored water (EB) consisted of four subjects whose patches were switched for the posttreatment test. Experimental Group ER received red-colored water and was exposed to the same conditions as EB. Subjects were restricted to $15 \mathrm{~min}$ access to $70 \mathrm{ml}$ of tap water per day; water jars were removed from the cages at all other times. Food jars were removed $2 \mathrm{~h}$ prior to water access and replaced $2 \mathrm{~h}$ later. Subjects were patched 4 days prior to the first exposure to colored water. The initial patching of the right or left eye was counterbalanced within groups.

Subjects were offered $70 \mathrm{ml}$ of either red- or blue-colored water in the usual container on the treatment day. Fifteen minutes following consumption, experimental subjects were injected with drug, and control subjects received distilled water. The next day patches were switched to the unpatched eye for those subjects in the "switch-patch" condition. Tests for aversion (measured by consumption) to the colored water were conducted on the 3 rd day following treatment.

\section{RESULTS}

An ANOVA for a 2 by 2 by 2 factorial design with an unweighted means analysis for unequal cells was used to identify significant main effects and interaction effects. The ANOVA revealed a significant main effect for the drug condition $(F=47.13, p<.001)$. No significant interactions were found.

A t test for related measures for within-group comparisons was conducted to determine the source of this significant F score. Figure 1 shows that an illnessinduced aversion was developed to the colored water CS. The comparison between combined control (no-drug) and combined experimental (drug) groups revealed a 


\section{Control
0}

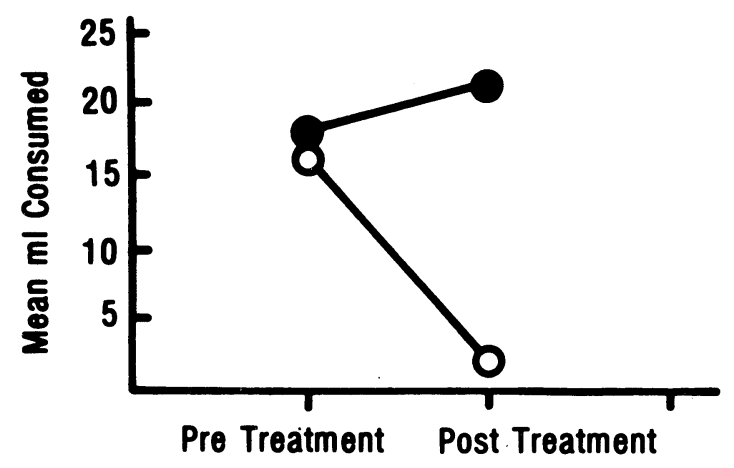

Days

Figure 1. Mean consumption of colored water for combined conditions.

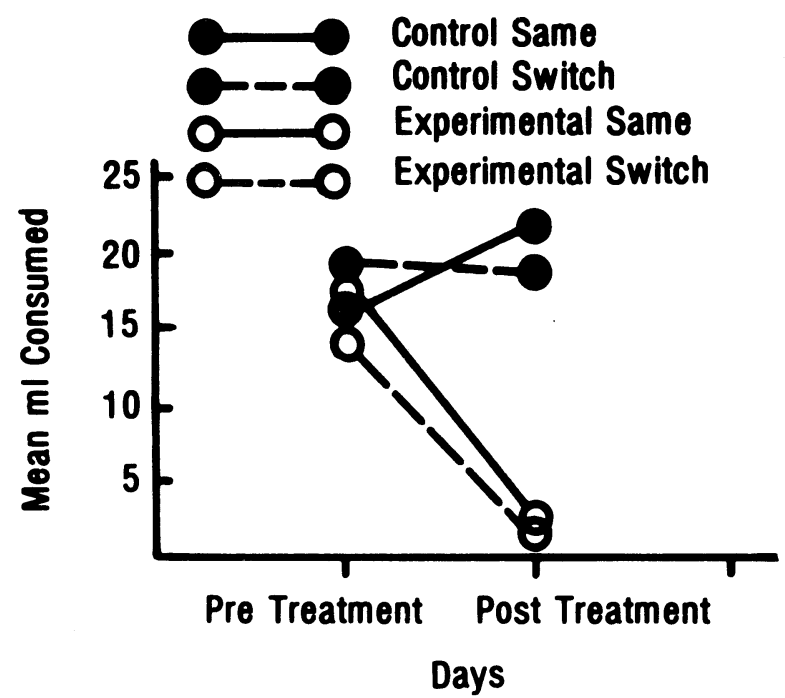

Figure 2. Mean consumption of colored water comparing same-side and switch-side patch conditions, combining color conditions.

significant difference $(p<.001)$. These results indicate that the effects were due to the drug (illness) alone.

Analysis of interocular transfer data shown in Figure 2 comparing same- and switch-side patching groups indicated that consumption levels did not differ between these groups.

\section{DISCUSSION}

The most notable findings in this study involved the comparisons between same-side control and experimental subjects and between switch-side control and experimental subjects. These comparisons indicated that not only can an illness-induced aversion be associated with color monocularly, but the aversion will subsequently transfer passively to the untrained eye (hemisphere).
Given the temporal relationship between the visual CS and the onset of the US, the interval between exposure to the CS and test ( 2 days), and the single exposure to the US, transfer in the present study appears to have been a robust phenomenon.

Donovan (1978) indicates that the decussation of the optic fibers may not be complete in the pigeon, stating that "a few uncrossed optic nerve fibers were reported as projecting to several ipsilateral thalamic nuclei" (p.410). Such would account for the direct "laying down" of visual information on the ipsilateral hemisphere. In this case, interocular transfer of anything is obviously possible.

Voneida and Mello (1975) suggest that intertectal commissures can provide another structure by which information may be laid directly upon the ipsilateral hemisphere when information is presented monocularly. The existence of such mechanisms would provide both hemispheres with immediate access to information regarding (in this case) the color CS. It is assumed that both also have access to the illness, since there is no reason to suspect laterality here.

Garcia, Hankins, and Rusiniak (1974), in discussing the relationship between gustatory stimuli and visceral feedback in the rat, conclude that the interaction of the two systems is uniquely suited for the learning of a relationship between food intake (flavor) and subsequent illness. They further suggest that the visual system of avians may fulfill the same function as the gustatory system in the rat, since the bird has a relatively undeveloped system of gustatory receptors and a more thoroughly developed visual system. It is possible that an analogous process by which afferents from the visceral system interact with those of the gustatory system in the rat is involved in the pigeon in terms of the visual system. Such interaction at subtectal levels may account for the demonstration of aversion with the untrained eye.

This study, while systematically replicating the work of others (e.g., Wilcoxin et al., 1971), extends the interocular transfer of visual information to color aversion in the pigeon.

\section{REFERENCE NOTE}

1. Hickis, C. F., \& Jackson, R. L. Failure to obtain blocking in illness induced aversion learning by pigeons: Implications? Paper presented at the Rocky Mountain Psychological Association, Denver, April 1978.

\section{REFERENCES}

Brett, L. P., Hankins, W. G., \& Garcia, J. Prey-lithium aversions: III. Buteo hawks. Behavioral Biology, 1976, 17, 87-98.

Catania, A. C. Interocular transfer of discriminations in the pigeon. Journal of the Experimental Analysis of Behavior, $1965,8,147-155$.

Cheney, C. D., \& TAM, V. Interocular transfer of a line tilt discrimination without mirror-image reversal using fading in pigeons. Journal of Biological Psychology, 1972, 14, 17-20.

Cowan, W. M., Adamson, L., \& Powell, T. P. S. An experimental study of the avian visual system. Journal of Anatomy, 1961, 95, 545-563.

Donovan, W. J. Structure and function of the pigeon visual system. Physiological Psychology, 1978, 6, 403-437.

Essock-Vitale, S. M. Pigeons' interhemispheric transfer of autoshaping and other visual discriminations. Physiology \& Behavior, 1979, 22, 1211-1215.

Garcia, J., Hankins, W. G., \& Rusiniak, K. W. Behavioral regulation of the milieu interne in man and rat. Science, 1974, 185, 824-831.

Graves, J. A., \& Goodale, M. A. Failure of interocular transfer in the pigeon. Physiology \& Behavior, 1977, 19, 425-428. GreEN, L., Brecha, N., \& Gazzaniga, M. S. Interocular trans- 
fer of simultaneous but not successive discriminations in the pigeon. Animal Learning \& Behavior, 1978, 6, 261-264.

LEVINE, J. Studies in the interrelation of central nervous structures in vision: III. Localization of the memory trace as evidenced by the lack of inter- and intra-ocular habit transfer in the pigeon. Journal of Genetic Psychology, 1952, 81, 19-27.

Mello, N. K. Interhemispheric reversal of mirror-image oblique lines after monocular training in pigeons. Science, 1965, 148, 252-254.

Stevens, V. J., \& Kirsch, W. R. Interocular transfer in pigeons of color discrimination but not motor response training. Animal Learning \& Behavior, in press.

Voneida, T. J., \& Mello, N. K. Interhemispheric projections of the optic tectum in pigeon. Brain Behavior and Evolution, 1975, 11, 91-108.

Wilcoxin, H. C., Dragoin, W. B., \& Kral, P. Illness induced aversions in rats and quail: Relative salience of visual and gustatory cues. Science, 1971, 171, 826-828.

(Received for publication December 28, 1979.) 